\title{
Regional alterations in cerebral growth exist preoperatively in infants with congenital heart disease
}

\author{
Cynthia Ortinau, MD, ${ }^{a}$ John Beca, MBChB, ${ }^{\mathrm{b}}$ Jennifer Lambeth, BS, ${ }^{\mathrm{a}}$ Barbara Ferdman, MD, ${ }^{\mathrm{a}}$ \\ Dimitrios Alexopoulos, MSc, ${ }^{\mathrm{a}}$ Joshua S. Shimony, MD, PhD ${ }^{\mathrm{c}}$ Michael Wallendorf, $\mathrm{PhD},{ }^{\mathrm{d}}$ \\ Jeffrey Neil, MD, PhD, ${ }^{\mathrm{a}, \mathrm{c}, \mathrm{e}}$ and Terrie Inder, $\mathrm{MD}^{\mathrm{a}, \mathrm{c}, \mathrm{e}}$
}

Objectives: Magnetic resonance imaging has been used to define the neurologic abnormalities in infants with
congenital heart disease (CHD), including preoperative injury and delayed brain maturation. The present study
used qualitative scoring, cerebral biometry, and diffusion imaging to characterize the preoperative brain
abnormalities in infants with CHD, including the identification of regions of greater vulnerability.

Methods: A total of 67 infants with CHD had preoperative magnetic resonance imaging scans available for analysis of brain injury using qualitative scoring and brain development using qualitative scoring, metrics, and diffusion imaging.

Results: Qualitative abnormalities were common, with $42 \%$ of infants having preoperative focal white matter lesions. Infants with CHD had smaller brain measures in the frontal lobe, parietal lobe, cerebellum, and brainstem $(P<.001)$, with the frontal lobe and brainstem displaying the greatest alterations $(P<.001)$. A smaller brain size in the frontal and parietal lobes correlated with delayed white matter microstructure reflected by diffusion imaging.

Conclusions: Infants with CHD commonly display brain injury and delayed brain development. Regional alterations in brain size are present, with the frontal lobe and brainstem demonstrating the greatest alterations. This might reflect a combination of developmental vulnerability and regional differences in cerebral circulation.

(J Thorac Cardiovasc Surg 2012;143:1264-70)

Supplemental material is available online.

Congenital heart disease (CHD) is the most common congenital lesion in the term infant and has long-lasting neurodevelopmental consequences during childhood and adolescence, with motor, cognitive, and behavioral impairments. ${ }^{1,2}$ To provide insight into the nature of the cerebral abnormalities in infants with CHD, neuroimaging with

From the Department of Pediatrics, ${ }^{\text {a }}$ St. Louis Children's Hospital and Washington University, St. Louis, Mo; Pediatric Intensive Care Unit, ${ }^{b}$ Starship Children's Hospital, Auckland, New Zealand; and Mallinkrodt Institute of Radiology, ${ }^{\mathrm{c}}$ Division of Biostatistics, ${ }^{\mathrm{d}}$ and Department of Neurology, ${ }^{\mathrm{e}}$ Washington University, St. Louis, Mo.

This research was supported by grants from the National Heart Foundation of New Zealand, Green Lane Research and Education Fund, Auckland Medical Research Fund, Doris Duke Charitable Foundation, National Institutes of Health under Ruth L. Kirschstein National Research Service Award T32 HD043010, National Institutes of Health grant K23 HD053212, and award P30HD062171 from the Eunice Kennedy Shriver National Institute of Child Health \& Human Development.

Disclosures: Authors have nothing to disclose with regard to commercial support.

Received for publication July 29, 2011; revisions received Sept 20, 2011; accepted for publication Oct 20, 2011; available ahead of print Dec 6, 2011.

Address for reprints: Cynthia Ortinau, MD, Department of Pediatrics, Washington University, 660 South Euclid, Campus Box 8116, St. Louis, MO 63110 (E-mail: Ortinau_c@kids.wustl.edu).

0022-5223/\$36.00

Copyright (c) 2012 by The American Association for Thoracic Surgery doi:10.1016/j.jtcvs.2011.10.039 magnetic resonance imaging (MRI) has been undertaken in several cohorts. These studies have demonstrated focal white matter abnormalities, periventricular leukomalacia, and infarct in up to $39 \%$ of infants before surgery. ${ }^{3-6}$ In addition, evaluations of brain maturation by qualitative scoring, ${ }^{7}$ magnetic resonance spectroscopy, ${ }^{4,6}$ and diffusion tensor imaging (DTI ${ }^{6}$ have suggested delays or impairment in brain development. DTI provides information regarding tissue microstructure and development using the measures of mean diffusivity (MD) and fractional anisotropy (FA). ${ }^{8}$ With cerebral maturation, MD decreases and FA increases. In contrast, both MD and FA decrease with acute injury. ${ }^{9,10}$ Infants with CHD have demonstrated greater MD and lower FA compared with healthy controls, consistent with maturational delay. ${ }^{6}$ In addition, volumetric analysis has been applied to fetal and neonatal MRI scans of infants with CHD and has demonstrated reductions in brain volume during the third trimester of pregnancy ${ }^{11}$ and postoperatively, particularly within the frontal lobe. ${ }^{12}$

Our study aimed to use qualitative scoring, cerebral biometry (a relatively simple measurement technique that has a strong correlation with volumetry ${ }^{13}$ ), and DTI on preoperative MRI scans to define the nature of preoperative brain abnormalities in infants with complex CHD. We hypothesized that infants with CHD would display regional alterations in brain growth and abnormalities in white matter microstructure that might differ in relation to their 


$$
\begin{aligned}
& \text { Abbreviations and Acronyms } \\
& \begin{aligned}
\text { CHD } & =\text { congenital heart disease } \\
\text { DEHSI } & =\text { diffuse excessive high-signal intensity } \\
\text { DTI } & \text { diffusion tensor imaging } \\
\text { FA } & =\text { fractional anisotropy } \\
\text { FOV } & \text { field of view } \\
\text { MD } & =\text { mean diffusivity } \\
\text { MRI } & =\text { magnetic resonance imaging } \\
\text { TE } & =\text { echo time } \\
\text { TR } & =\text { repetition time }
\end{aligned}
\end{aligned}
$$

primary cardiac diagnosis. The present study was a part of a larger prospective longitudinal cohort of CHD infants who underwent MRI preoperatively, postoperatively, and at 3 months of age, as well as neurodevelopmental follow-up examinations at 2 years of age.

\section{MATERIALS AND METHODS \\ Patients}

This was a prospective longitudinal study conducted from March 2005 to November 2008 at Starship Children's Hospital in Auckland, New Zealand involving infants with complex CHD who underwent cardiac surgery at less than 8 weeks of age. The patients were excluded if they had been born at less than 36 weeks' gestation or more than 48 weeks postmenstrual age, had a pre-existing neurologic deficit unrelated to the cardiovascular defect, had a chromosomal abnormality or syndrome, had moderate or severe extracardiac anomalies, had previous cardiac surgery, required extracorporeal membrane oxygenation preoperatively, or were unable to undergo preoperative MRI. The infants were separated into 1 of 4 cardiac diagnostic groupings according to a classification previously described by Clancy and colleagues ${ }^{14}$ : single-ventricle circulation, single-ventricle circulation with aortic arch anomaly, 2 ventricle circulation, and 2 ventricle circulation with aortic arch anomaly. ${ }^{14}$ All parents provided written informed consent, and the ethics committees for Starship Children's Hospital and Washington University (St. Louis, MO) approved the study. Also, 36 healthy term infants from Royal Children's Hospital (Melbourne, Australia) were recruited for control purposes and underwent brain MRI at that time.

\section{MRI Acquisition}

Preoperative MRI was performed when the infants were clinically stable. Those who had balloon atrial septostomy underwent MRI after the septostomy was performed. MRI was performed using a 1.5T Magnetom Avanto (Siemens, Erlangen, Germany) with the following sequences: (1) coronal $\mathrm{T}_{2}$-weighted turbo-spin echo sequences, 2 -mm slice thickness, repetition time (TR) of $4510 \mathrm{~ms}$, echo time (TE) of 79 and $158 \mathrm{~ms}$, flip angle of $150^{\circ}$, and field of view (FOV) of $192 \times 192$; (2) transverse $\mathrm{T}_{2}$-weighted sequences, 3-mm slice thickness, TR of $4140 \mathrm{~ms}$, TE of $158 \mathrm{~ms}$, flip angle of $150^{\circ}$, and FOV of $160 \times 160$; (3) coronal 3-dimensional fast fluid attenuated inversion recovery $\mathrm{T}_{1}$-weighted images with 1 -mm slice thickness, TR of $10 \mathrm{~ms}$, TE of $4.8 \mathrm{~ms}$, flip angle of $15^{\circ}$, and FOV of $192 \times 192$; and (4) diffusion-weighted images, 4-mm slice thickness in 20 directions with $\mathrm{b}$ amplitudes of 0 and $1000 \mathrm{~mm}^{2} / \mathrm{s}$, TR of 3200 to $3600 \mathrm{~ms}$, TE of $96 \mathrm{~ms}$, flip angle of $90^{\circ}$, and FOV of $128 \times 128$. The control data from 36 healthy-term infants were used for comparison in the metric analysis ( $\mathrm{T}_{2}$-weighted images only). The images were obtained using a $1.5 \mathrm{~T}$ Sigma System MRI system (GE Healthcare, Milwaukee, WI) with $\mathrm{T}_{2}$-weighted, dual-echo, fast spin-echo sequences, with a 2-mm slice thickness, TR of $4000 \mathrm{~ms}$, TE of $60 / 160 \mathrm{~ms}$, and FOV of $220 \times 160$. No data for the DTI acquisition from term controls without $\mathrm{CHD}$ were acquired or available.

\section{Qualitative Scoring}

A standardized scoring system was used to evaluate 10 different variables within the white and gray matter for brain injury and maturation. ${ }^{15,16}$ Two independent raters (C.O., T.I.) assessed the white matter for focal white matter signal abnormality, diffuse excessive high-signal intensity (DEHSI), hemorrhage, ventricular size, white matter volume, and myelination in the posterior limb of the internal capsule. Gray matter was assessed for amount of extra-axial space, maturation of gyrification, abnormality in the deep nuclear gray matter, and other abnormalities. A score of 1 to 4 was assigned to each variable, with 1 considered normal; 2 , mild abnormality; 3 , moderate abnormality; and 4, severe abnormality (Figure 1). For focal white matter signal abnormalities, 1 or 2 focal lesions was considered mild; 3 to 5 lesions, moderate; and greater than 5 lesions, severe.

\section{Brain Metrics}

Simple brain metrics were measured on $\mathrm{T}_{2}$-weighted images, as described previously. ${ }^{13}$ Two independent raters (J.L., C.O.) measured 19 parameters for 9 tissue distances (right and left frontal height, right and left frontal length, bifrontal diameter, bone biparietal diameter, brain biparietal diameter, transverse cerebellar diameter, and brainstem area) and 10 fluid distances (third ventricle, interhemispheric distance, right and left extraaxial fluid space, right and left craniocaudal interopercular distances, right and left anteroposterior interopercular distances, and right and left ventricular diameters) across 5 slices in the coronal or axial view (Figure 1). Simple brain metrics were also performed for 36 healthy term control infants.

\section{Diffusion Imaging}

The diffusion images were registered to a term control neonatal atlas and reconstructed to $2 \times 2 \times 2 \mathrm{~mm}^{3}$. Parametric maps were generated for $\mathrm{MD}$, relative anisotropy, FA, and eigenvalues $\left(\lambda_{1}, \lambda_{2}\right.$, and $\left.\lambda_{3}\right)$. The measures of axial $\left(\lambda_{1}\right)$ and radial $\left(\left(\lambda_{2}+\lambda_{3}\right) / 2\right)$ diffusivity were recorded. Diffusion encodings corrupted by subject motion were automatically removed, and a residual map was created to determine the variance in the reconstructed data. DTI parameter sampling was performed using Analyze, version 9.0 (Mayo Clinic, Rochester, MN). The regions of interest were placed in 7 white matter regions: genu and splenium of the corpus collosum, posterior limb of the internal capsule, frontal white matter, subcortical white matter, optic radiation, and centrum semiovale (Figure 1). Inter-rater reliability testing on 9 infants provided an intraclass correlation coefficient of 0.98 (95\% confidence interval, 0.97-0.98).

\section{Statistical Analysis}

Statistical analysis was performed using the Statistical Package for Social Sciences, version 17.0 (SPSS, Chicago, IL) and SAS, version 9.2 (SAS Institute, Cary, NC). The comparisons between CHD infants and control infants were done using a $t$ test for continuous variables and chi-square test or Fisher's exact test for categorical variables. Comparisons across the groups of CHD infants were performed using an analysis of variance with Bonferroni's correction for continuous variables and chi-square analysis for categorical variables. Analysis of covariance was performed to control for covariates, with brain metrics as the dependent variable and postmenstrual age at MRI, birth weight, and gender as the covariates. The brain diameters were also analyzed with a mixed model approach to assess for regional variations. The variables of group, region, and group by region interaction were fixed effects, and the infant within-group was a random effect. The brainstem area was analyzed using analysis of variance on group. Pearson's correlations were used for diffusion values, focal signal abnormality, and metrics. Then, partial correlations were performed on significant correlations to control for postmenstrual age at MRI. 

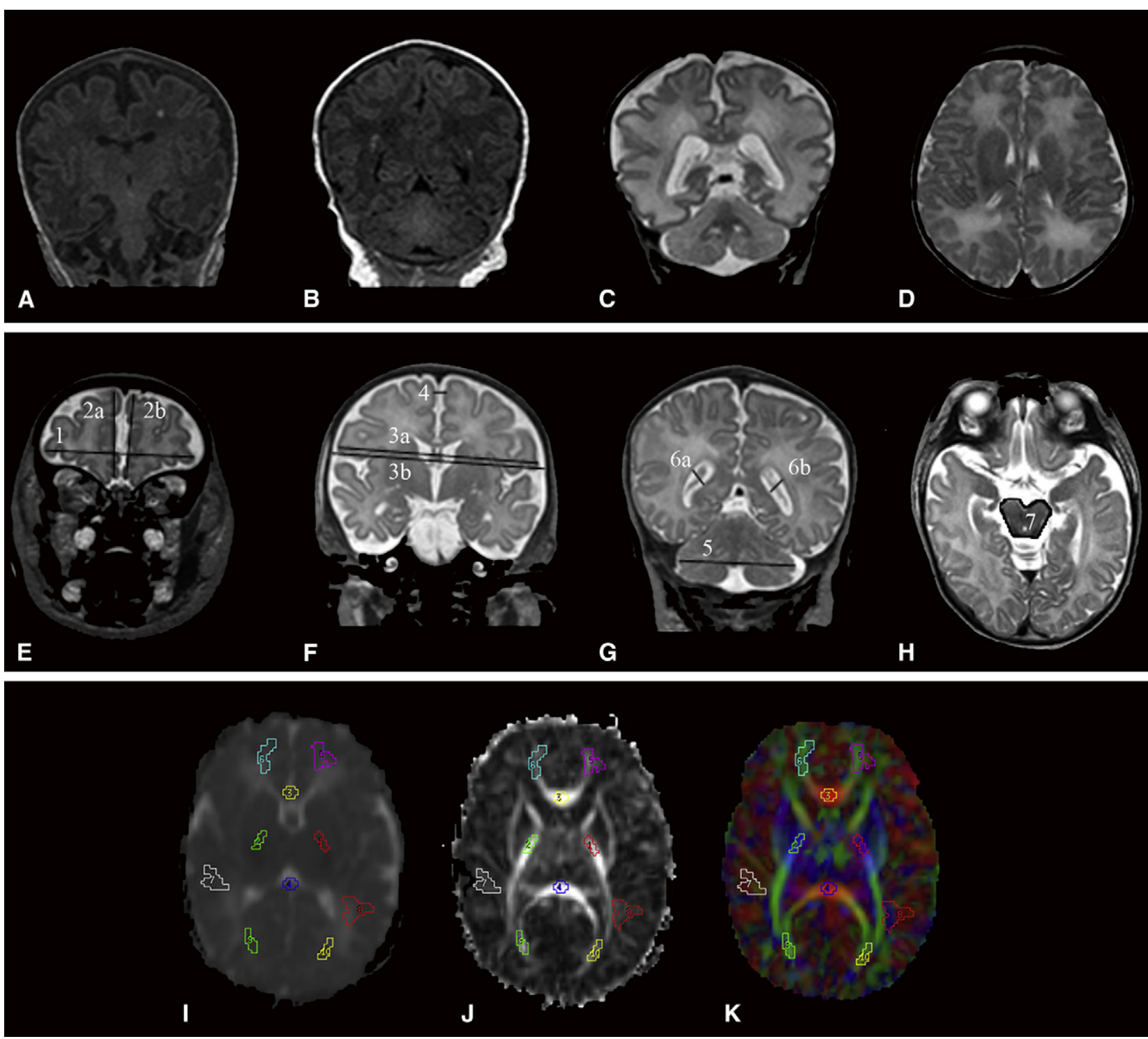

FIGURE 1. A-D, Qualitative scoring abnormalities. A, $\mathrm{T}_{1}$-weighted image with abnormalities that included focal signal abnormality, delayed myelination in posterior limb of the internal capsule, increased extra-axial space, and delayed gyrification. $\mathrm{B}, \mathrm{T}_{1}$-weighted image with bilateral focal signal abnormalities and delayed gyrification. $\mathrm{C}, \mathrm{T}_{2}$-weighed image with ventriculomegaly, diffuse excessive high-signal intensity (DEHSI), increased extra-axial space, and moderate-to-severe delay in gyrification. D, $\mathrm{T}_{2}$-weighted image with DEHSI. E-H, Subset of brain metrics. 1, Bifrontal diameter; 2a, right frontal height; $2 \mathrm{~b}$, left frontal height; 3a, brain biparietal diameter; 3b, bone biparietal diameter; 4, interhemispheric distance; 5, transverse cerebellar diameter; 6a, right ventricular diameter; 6b, left ventricular diameter; and 7, brainstem area. I-K, Diffusion imaging: I, mean diffusivity; J, fractional anisotropy; K, red, green, blue color plot. Regions of interest were the same for each image (from top to bottom): left and right frontal white matter, genu of the corpus collosum, left and right posterior limb of the internal capsule, splenium of the corpus collosum, left and right subcortical white matter, and left and right optic radiation.

\section{RESULTS}

\section{Patient Population}

The parents of 71 infants agreed and the infants were enrolled in the present study. One infant was excluded for a previously undiagnosed genetic abnormality [45XY, der $(13 ; 14)(\mathrm{q} 10 ; \mathrm{q} 10)]$ and 3 were excluded because of poorquality MRI, for 67 subjects available for analysis.

Of the 67 infants, 10 were classified as having single ventricle circulation. Of these 10 infants, 9 had pulmonary atresia (6 with isolated, 2 with tetrology of Fallot, and 1 with Ebstein's anomaly) and 1 had complex heterotaxy, total anomalous pulmonary venous drainage, and an atrioventricular canal. Another 16 infants were classified as having single ventricle circulation with an aortic arch anomaly, with 14 having hypoplastic left heart syndrome and 2 having more complex lesions. A total of 27 infants were classified having 2 ventricle circulation, with most $(n=24)$ having transposition of the great arteries, of whom only 4 
infants had a ventricular septal defect. Two infants had double outlet right ventricle, and 1 had total anomalous pulmonary venous drainage. Fourteen infants were classified as having 2 ventricle circulation with an aortic arch anomaly, 1 with truncus arteriosus and an interrupted aortic arch, 5 with coarctation, 4 with interrupted aortic arch, and 4 with a hypoplastic aortic arch. The infants with single ventricle circulation with an aortic arch anomaly were more likely to be diagnosed antenatally $(P<.01)$. No differences were found in any other patient characteristic across the CHD diagnostic groupings (Table E1).

The infants with CHD did not differ in gestational age, gender, birth weight, or weight at MRI compared with the term born infants without CHD. The infants with CHD underwent MRI scanning at an earlier postnatal age than the control infants (CHD 8 days versus control 15 days, $P<.001)$. None of the MRI scans were performed because of clinical neurologic concerns, and infants with abnormalities on the MRI scans did not display any obvious symptoms.

\section{MRI Qualitative Scoring}

Focal white matter signal abnormalities were present in $42 \%(\mathrm{n}=28)$, and DEHSI was present in $96 \%(\mathrm{n}=64)$ of infants, most of which were mild abnormalities. Of the infants with focal white matter signal abnormalities, $75 \%$ (21/28) had a mild abnormality, $14 \%$ had a moderate abnormality (4/28), and $11 \%$ had a severe abnormality (3/28). Hemorrhage occurred in 2 infants, both of which were small intraventricular hemorrhages (Table 1). Increased extraaxial fluid space was present in $51 \%$ of the infants $(\mathrm{n}=34)$, and delayed gyrification was present in $64 \%$ $(\mathrm{n}=43$; Table 2$)$. No infants had infarcts preoperatively. Three infants had abnormalities classified as "other": 1 with sinus venous thrombosis, 1 with isolated temporal lobe diffusion restriction that was not typical in its distribution for focal infarction, and 1 with cerebellar hemorrhage. No difference was found among the cardiac groups for the individual scoring variables.

\section{Brain Metrics}

After controlling for birth weight, postmenstrual age at MRI, and gender, CHD infants displayed smaller brain tissue measures than control infants in the frontal lobe, parietal lobe, cerebellum, and brainstem (Table 3). CHD infants had smaller measures of the left extra-axial fluid space $(P<.001)$ but larger fluid measures in the right $(P<.01)$ and left $(P<.001)$ craniocaudal interoperculum.

To evaluate for regional differences in brain size, the relative difference was calculated for the bifrontal diameter, biparietal diameter, transverse cerebellar diameter, and brainstem area in CHD infants, with reference to the control infants. Although CHD infants had smaller measures in all these regions, the greatest effect was seen in the frontal lobe $(P<.001)$ and brainstem $(P<.001$; Figure 2$)$. A strong
TABLE 1. Qualitative scoring of white matter variables

\begin{tabular}{|c|c|c|c|c|c|}
\hline $\begin{array}{c}\text { White matter } \\
\text { variable }\end{array}$ & $\begin{array}{c}\text { SV } \\
(\mathbf{n}=\mathbf{1 0})\end{array}$ & $\begin{array}{c}\text { SVA } \\
(\mathbf{n}=\mathbf{1 6})\end{array}$ & $\begin{array}{c}2 \mathrm{~V} \\
(\mathrm{n}=27)\end{array}$ & $\begin{array}{c}2 \mathrm{VA} \\
(\mathrm{n}=14)\end{array}$ & $\begin{array}{c}\text { Total } \\
(n=67)\end{array}$ \\
\hline \multicolumn{6}{|l|}{ Focal signal (n) } \\
\hline Normal & 5 & 10 & 17 & 7 & 39 \\
\hline Mild & 2 & 5 & 8 & 6 & 21 \\
\hline Moderate & 2 & 1 & 1 & 0 & 4 \\
\hline Severe & 1 & 0 & 1 & 1 & 3 \\
\hline \multicolumn{6}{|l|}{ DEHSI (n) } \\
\hline Normal & 1 & 1 & 0 & 1 & 3 \\
\hline Mild & 6 & 11 & 19 & 9 & 45 \\
\hline Moderate & 3 & 4 & 8 & 3 & 18 \\
\hline Severe & 0 & 0 & 0 & 1 & 1 \\
\hline \multicolumn{6}{|l|}{ Hemorrhage (n) } \\
\hline Normal & 9 & 16 & 26 & 14 & 65 \\
\hline Mild & 1 & 0 & 1 & 0 & 2 \\
\hline Moderate & 0 & 0 & 0 & 0 & 0 \\
\hline Severe & 0 & 0 & 0 & 0 & 0 \\
\hline \multicolumn{6}{|l|}{ Ventricular size (n) } \\
\hline Normal & 5 & 7 & 13 & 4 & 29 \\
\hline Mild & 2 & 9 & 13 & 9 & 33 \\
\hline Moderate & 3 & 0 & 1 & 1 & 5 \\
\hline Severe & 0 & 0 & 0 & 0 & 0 \\
\hline \multicolumn{6}{|l|}{ Volume (n) } \\
\hline Normal & 6 & 10 & 9 & 8 & 33 \\
\hline Mild & 3 & 6 & 18 & 6 & 33 \\
\hline Moderate & 1 & 0 & 0 & 0 & 1 \\
\hline Severe & 0 & 0 & 0 & 0 & 0 \\
\hline \multicolumn{6}{|c|}{ Myelination in PLIC (n) } \\
\hline Normal & 3 & 11 & 16 & 6 & 36 \\
\hline Mild & 6 & 4 & 11 & 7 & 28 \\
\hline Moderate & 1 & 1 & 0 & 1 & 3 \\
\hline Severe & 0 & 0 & 0 & 0 & 0 \\
\hline
\end{tabular}

$S V$, Single ventricle circulation; $S V A$, single ventricle circulation with aortic arch anomaly; $2 \mathrm{~V}, 2$ ventricle circulation; $2 \mathrm{VA}, 2$ ventricle circulation with aortic arch anomaly; DEHSI, diffuse excessive high-signal intensity; PLIC, posterior limb of internal capsule.

correlation was found between the frontal and parietal $(r=0.73, P<.001)$, frontal and cerebellar $(r=0.47$, $P<.001)$, and parietal and cerebellar $(r=0.54, P<.001)$ measures. In contrast, the brainstem area had weaker correlations with the parietal $(r=0.27, P<.05)$ and cerebellar $(r=0.29, P<.05)$ measures and no correlation to the frontal measure $(r=0.02, P=\mathrm{NS})$.

When the cardiac groups were compared, those with single ventricle circulation had a smaller brainstem area than infants with 2 ventricle circulation $(P<.05)$. However, after controlling for birth weight, postmenstrual age at MRI, and gender, no differences were found in brain metrics among the cardiac groups (Table 3 ).

\section{Relationship Between Injury and Brain Maturation and Growth}

The presence of focal white matter signal abnormalities did not relate to the presence of increased extra-axial space $(P=.70)$, delayed gyrification $(P=.30)$, or myelination in 
TABLE 2. Qualitative scoring of gray matter variables

\begin{tabular}{|c|c|c|c|c|c|}
\hline Gray matter variable & $\begin{array}{c}\text { SV } \\
(\mathbf{n}=\mathbf{1 0})\end{array}$ & $\begin{array}{c}\text { SVA } \\
(n=16)\end{array}$ & $\begin{array}{c}2 V \\
(n=27)\end{array}$ & $\begin{array}{c}2 \mathrm{VA} \\
(\mathrm{n}=14)\end{array}$ & $\begin{array}{c}\text { Total } \\
(n=67)\end{array}$ \\
\hline \multicolumn{6}{|l|}{ Extra-axial space (n) } \\
\hline Normal & 5 & 8 & 13 & 7 & 33 \\
\hline Mild & 5 & 7 & 14 & 6 & 32 \\
\hline Moderate & 0 & 1 & 0 & 1 & 2 \\
\hline Severe & 0 & 0 & 0 & 0 & 0 \\
\hline \multicolumn{6}{|l|}{$\begin{array}{l}\text { Maturation of } \\
\quad \text { gyrification (n) }\end{array}$} \\
\hline Normal & 4 & 6 & 11 & 3 & 24 \\
\hline Mild & 4 & 9 & 16 & 10 & 39 \\
\hline Moderate & 2 & 1 & 0 & 1 & 4 \\
\hline Severe & 0 & 0 & 0 & 0 & 0 \\
\hline \multicolumn{6}{|l|}{$\begin{array}{c}\text { Deep nuclear gray } \\
\text { matter (n) }\end{array}$} \\
\hline Normal & 7 & 10 & 24 & 12 & 53 \\
\hline Mild & 3 & 5 & 3 & 2 & 13 \\
\hline Moderate & 0 & 1 & 0 & 0 & 1 \\
\hline Severe & 0 & 0 & 0 & 0 & 0 \\
\hline \multicolumn{6}{|l|}{ Other abnormality (n) } \\
\hline Normal & 9 & 16 & 26 & 13 & 64 \\
\hline Mild & 1 & 0 & 1 & 0 & 2 \\
\hline Moderate & 0 & 0 & 0 & 1 & 1 \\
\hline Severe & 0 & 0 & 0 & 0 & 0 \\
\hline
\end{tabular}

$S V$, Single ventricle circulation; SVA, single ventricle circulation with aortic arch anomaly; $2 \mathrm{~V}, 2$ ventricle circulation; $2 V A, 2$ ventricle circulation with aortic arch anomaly.

the posterior limb of the internal capsule $(P=.98)$. In addition, focal white matter signal abnormalities did not relate to brain metrics in the bifrontal diameter $(P=.53)$, biparietal diameter $(P=.97)$, transverse cerebellar diameter $(P=.95)$, or brainstem area $(P=.51)$.

\section{Diffusion Imaging}

Of the 67 infants included in the present study, 26 had 20direction diffusion data acquired, of which 7 were excluded because of poor quality, leaving the data sets of 19 infants for analysis. The clinical characteristics of infants with DTI data did not differ from the characteristics of all CHD infants. A strong correlation was found between the diffusion values from the right and left hemispheres; therefore, additional analysis was only performed on measures from the left hemisphere. Because no data were available using this DTI acquisition in term born control infants, we could not evaluate the effect of CHD on DTI. However, within the CHD cohort, we evaluated the relationship of focal white matter signal abnormality and brain growth with DTI microstructural measures. After controlling for postmenstrual age at MRI, no relationships were found between the focal signal abnormality and diffusion measures. Analysis of the 4 regional brain metrics revealed that smaller brain measures in the frontal lobe and parietal lobe correlated with greater MD and radial diffusivity and lower FA values, which were most consistent in the posterior limb of the internal capsule (Table E2). An analysis among the cardiac groups was not undertaken for diffusion measures owing to the small sample size.

\section{DISCUSSION}

The results of the present study have confirmed and extended previous reports demonstrating that infants with CHD have high rates of focal white matter lesions and less mature brains preoperatively. Importantly, our study is the first to demonstrate preoperative regional variation in impaired growth, with the frontal lobes and brainstem the more severely affected areas. In addition, we confirmed the lack of a relationship between white matter injury and any measure of delayed brain growth or maturity, suggesting that influences on impaired brain growth occur independently of focal white matter injury.

Preoperative cerebral abnormalities are common in infants with CHD, including focal white matter injury, periventricular leukomalacia, and infarct. ${ }^{3-6}$ We identified a high rate of preoperative focal white matter lesions, occurring in $42 \%$ of our cohort. It is important to note that our previously published data demonstrated white matter injury in $27 \%$ of infants; however, this included our cohort and infants from another center (Royal Children's Hospital, Melbourne, Australia) and excluded infants with 2 ventricle circulation with aortic arch anomaly physiology. ${ }^{3}$ In the present cohort, we also evaluated DEHSI and found this form of signal abnormality in

TABLE 3. Comparison of preoperative brain metrics in controls and infants with CHD

\begin{tabular}{|c|c|c|c|c|c|c|c|c|}
\hline Mean measurement $(\mathrm{cm})$ & $\begin{array}{l}\text { Control } \\
(n=36)\end{array}$ & $\begin{array}{c}\text { SV } \\
(\mathbf{n}=\mathbf{1 0})\end{array}$ & $\begin{array}{c}\text { SVA } \\
(n=16)\end{array}$ & $\begin{array}{c}2 V \\
(n=27)\end{array}$ & $\begin{array}{c}2 \mathrm{VA} \\
(\mathrm{n}=14)\end{array}$ & $\begin{array}{l}\text { All CHD } \\
(n=67)\end{array}$ & $\begin{array}{c}\text { Mean difference* } \\
(95 \% \text { CI })\end{array}$ & $P$ value \\
\hline Right frontal height & 4.98 & 3.96 & 4.08 & 3.89 & 4.11 & 3.99 & $-0.99(-1.24$ to -0.75$)$ & $<.001$ \\
\hline Left frontal height & 4.93 & 3.89 & 4.07 & 3.85 & 4.03 & 3.95 & $-0.99(-1.23$ to -0.74$)$ & $<.001$ \\
\hline Bifrontal diameter & 7.25 & 6.12 & 6.39 & 6.18 & 6.43 & 6.27 & $-0.97(-1.18$ to -0.76$)$ & $<.001$ \\
\hline Bone biparietal diameter & 8.93 & 8.28 & 8.61 & 8.56 & 8.57 & 8.53 & $-0.40(-0.58$ to -0.22$)$ & $<.001$ \\
\hline Brain biparietal diameter & 8.53 & 7.77 & 8.12 & 8.06 & 8.16 & 8.05 & $-0.48(-0.67$ to -0.29$)$ & $<.001$ \\
\hline Transverse cerebellar diameter & 5.56 & 5.18 & 5.20 & 5.33 & 5.26 & 5.26 & $-0.30(-0.42$ to -0.19$)$ & $<.001$ \\
\hline Brainstem area & 2.74 & 2.05 & 2.20 & 2.40 & 2.22 & 2.26 & $-0.48(-0.62$ to -0.33$)$ & $<.001$ \\
\hline
\end{tabular}

$S V$, Single ventricle circulation; $S V A$, single ventricle circulation with aortic arch anomaly; $2 V, 2$ ventricle circulation; $2 V A, 2$ ventricle circulation with aortic arch anomaly. $*$ Difference between control infants and all CHD infants. 


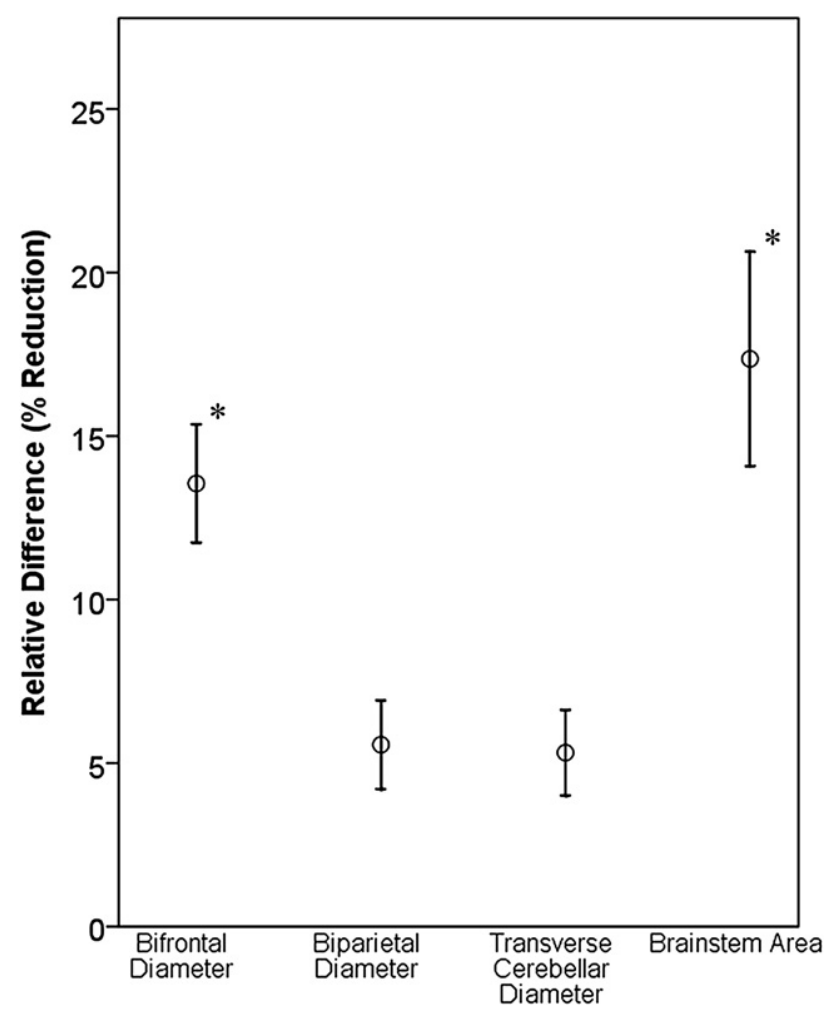

FIGURE 2. Relative difference in regional brain metrics. $* P<.001$ compared with brain biparietal diameter and transverse cerebellar diameter.

$96 \%$ of CHD infants. The presence of DEHSI appears to relate to diffusion measures in preterm infants, ${ }^{17}$ but the visual assessment of this signal abnormality has low inter- and intraobserver agreement. ${ }^{18}$ In addition, the neurodevelopmental significance of DEHSI remains unclear. Thus, we limited our definition of white matter injury to focal signal abnormalities instead of including DEHSI.

The delay in cerebral development on MRI has been classified using a variety of techniques in infants with CHD. Using a maturation scoring system, term infants with $\mathrm{CHD}$ have been shown to have a 4-week delay in development. ${ }^{7}$ Maturational delay in brain microstructure, with an increase in average diffusivity and a decrease in FA, has also been shown at term in CHD infants and found to be unrelated to visible injury. ${ }^{6}$ This delay in brain development appears to evolve in the third trimester of pregnancy, suggesting slowed growth as early as the fetal setting. ${ }^{11}$

In our study, extra-axial space and maturation of gyrification were used to qualitatively evaluate brain growth and demonstrated abnormalities in $51 \%$ and $64 \%$ of our infants, respectively. We also evaluated growth using simple brain metrics and demonstrated a smaller brain size in infants with CHD. Focal white matter signal abnormality did not correlate with impaired brain growth, suggesting that the reduction in brain size occurred independently of visible qualitative abnormalities. A relationship was found between the frontal and parietal measures and diffusion measures, suggesting that delayed maturation at the microstructural level in these supratentorial regions accompanies poor growth.

Our data report new findings in relation to the regional nature of alterations in brain size preoperatively, with the frontal lobe and brainstem having the greatest alterations. Data are limited on the regional effects in CHD. A postoperative study at 15 months of age showed a reduction in gray matter volume, most prominently in the frontal lobe, and a decrease in the frontal lobe white matter. ${ }^{12}$ Our data are consistent with the data from that study suggesting regional vulnerability in the frontal lobe. ${ }^{12}$ In addition, we also found a major difference in the brainstem area. Importantly, these findings were present preoperatively. The consequences of these regional alterations remain unclear.

With regard to the regional vulnerability of the frontal lobes, one might hypothesize that such vulnerability is related to differences in the rates of brain development, with the frontal lobe being an area of relative immaturity at term equivalent postmenstrual age. Synaptogenesis occurs from the third trimester throughout the first 2 years of life and is followed by pruning (or synapse elimination), both of which are most protracted in the prefrontal cortex. ${ }^{19}$ Peak FA values on diffusion imaging occur later in the frontal lobe than in other regions and remain greater at term gestation, suggesting greater immaturity within this region at term, with a more protracted developmental trajectory. ${ }^{20}$ Volumetric studies have supported these frontal lobe findings, showing peak volumes of frontal lobe gray matter occurring around puberty. ${ }^{21}$ This immaturity and delayed trajectory might predispose this region to injury. ${ }^{22}$ Nonetheless, the effect of impairment in frontal growth in infants with $\mathrm{CHD}$ at term equivalent on later expansion of the frontal lobe and its function are unknown.

An additional mechanism of vulnerability to the frontal lobe regions might relate to selective alterations in the anterior cerebral circulation in infants with CHD. A reduced pulsatility index in the middle cerebral artery is a marker of cerebral blood flow redistribution and is associated with adverse perinatal outcomes and abnormal neurobehavior in small for gestational age infants. ${ }^{23}$ Infants with CHD have been shown to have a decrease in the cerebral/placental resistance ratio, which has been associated with a smaller head circumference at birth. ${ }^{24}$ However, regional blood flow measures have not been undertaken in infants with CHD and are worthy of future investigation.

The etiology of the sensitivity of the brainstem to growth alterations remains unclear. In an effort to better delineate whether the brainstem size reflected delayed growth in other brain regions, we examined the correlations between the brainstem and other measures. Brainstem size had no correlation with the size of the frontal lobe and only correlated very weakly with the size of the parietal lobe and cerebellum, suggesting that there might be independent 
mechanisms influencing the development of the brainstem. To further support evidence of different mechanisms of growth impairment within the supra- and infratentorial regions in infants with CHD, we found differential correlations between smaller brain measures and altered white matter diffusion. Disturbances in white matter microstructure were related to cerebral growth in the frontal and parietal regions, but not to cerebellar or brainstem growth. This emphasizes the importance of regional investigations of cerebral development.

We did not find any relationship between white matter injury and delayed brain growth or maturity. This finding appeared to be consistent across all assessments of growth and maturity-qualitative scoring, quantitative brain metrics, and diffusion measures. Miller and colleagues ${ }^{6}$ described similar findings with evidence of delayed maturation by diffusion and spectroscopy that was unrelated to brain injury. However, an association between cerebral immaturity and white matter injury has been described in other data. ${ }^{25}$

It is currently unclear how these preoperative findings affect clinical and neurodevelopmental outcomes. Alterations in the frontal lobe volume in infants with CHD at 15 months of age appear to relate to motor performance. ${ }^{12}$ However, there are no data reporting the relationship between preoperative brain MRI findings (injury or maturation) and neurologic outcome, making this an area worthy of future investigation. The ability to fully characterize the nature and timing of cerebral abnormalities and the long-term effect of these lesions might provide insight into practice changes or potential neuroprotective interventions.

The primary limitation of the present study is the lack of term born control infants with diffusion imaging. Because our control infants had different MRI acquisitions, we could not reliably compare the diffusion values. There might also be regional- or lesion-specific differences in diffusion that we were unable to delineate owing to the small sample size.

\section{CONCLUSIONS}

Our findings have confirmed that preoperative cerebral abnormalities, including delayed maturation and white matter injury, are common in infants with CHD. Our additional new findings include regional vulnerability with more pronounced abnormalities in the frontal lobe and brainstem. This might be secondary to the regional differences in normal brain development and/or regional alterations in cerebral circulation. However, additional studies are needed to investigate the mechanisms and timing of these abnormalities and how they relate to clinical and neurologic outcomes.

\section{References}

1. Bellinger DC, Wypij D, duPlessis AJ, Rappaport LA, Jonas RA, Wernovsky G, et al. Neurodevelopmental status at eight years in children with dextrotransposition of the great arteries: The Boston Circulatory Arrest Trial. J Thorac Cardiovasc Surg. 2003;126:1385-96.
2. Majnemer A, Limperopoulos C, Shevell M, Rohlicek C, Rosenblatt B, Tchervenkov C. Developmental and functional outcomes at school entry in children with congenital heart defects. J Pediatr. 2008;153:55-60.

3. Beca J, Gunn J, Coleman L, Hope A, Whelan L-C, Gentles T, et al. Preoperative brain injury in newborn infants with transposition of the great arteries occurs at rates similar to other complex congenital heart disease and is not related to balloon atrial septostomy. J Am Coll Cardiol. 2009;53:1807-11.

4. Mahle WT, Tavani F, Zimmerman RA, Nicolson SC, Galli KK, Gaynor JW, et al. An MRI study of neurological injury before and after congenital heart surgery. Circulation. 2002;106:I109-14

5. McQuillen PS, Barkovich AJ, Hamrick SE, Perez M, Ward P, Glidden DV, et al. Temporal and anatomic risk profile of brain injury with neonatal repair of congenital heart defects. Stroke. 2007;38:736-41.

6. Miller SP, McQuillen PS, Hamrick S, Xu D, Glidden D, Charlton N, et al. Abnormal brain development in newborns with congenital heart disease. $N$ Engl J Med. 2007;357:1928-38.

7. Licht DJ, Shera DM, Clancy RR, Wernovsky G, Montengro LM, Nicolson SC, et al. Brain maturation is delayed in infants with complex congenital heart defects. J Thorac Cardiovasc Surg. 2009;137:529-37.

8. Beaulieu C. The basis of anisotropic water diffusion in the nervous system-A technical review. NMR Biomed. 2002;15:435-55.

9. Neil J, Miller J, Mukherjee P, Huppi PS. Diffusion tensor imaging of normal and injured developing human brain-A technical review. NMR Biomed. 2002;15: 543-52.

10. Huppi PS, Dubois J. Diffusion tensor imaging of brain development. Semin Fetal Neonatal Med. 2006;11:489-97.

11. Limperopoulos C, Tworetzky W, McElhinney DB, Newburger JW, Brown DW, Robertson RL, et al. Brain volume and metabolism in fetuses with congenital heart disease: Evaluation with quantitative magnetic resonance imaging and spectroscopy. Circulation. 2010;121:26-33.

12. Watanabe K, Matsui M, Matsuzawa J, Tanaka C, Noguchi K, Yoshimura N, et al. Impaired neuroanatomic development in infants with congenital heart disease. $J$ Thorac Cardiovasc Surg. 2009;137:146-53.

13. Nguyen The Tich S, Anderson PJ, Shimony JS, Hunt RW, Doyle LW, Inder TE. A novel quantitative simple brain metric using MR imaging for preterm infants. AJNR Am J Neuroradiol. 2009;30:125-31.

14. Clancy RR, McGaurn SA, Wernovsky G, Spray TL, Norwood WI, Jacobs ML, et al. Preoperative risk-of-death prediction model in heart surgery with deep hypothermic circulatory arrest in the neonate. J Thorac Cardiovasc Surg. 2000;119:347-57.

15. Inder TE, Wells SJ, Mogridge NB, Spencer C, Volpe JJ. Defining the nature of the cerebral abnormalities in the premature infant: A qualitative magnetic resonance imaging study. J Pediatr. 2003;143:171-9.

16. Woodward LJ, Anderson PJ, Austin NC, Howard K, Inder TE. Neonatal MRI to predict neurodevelopmental outcomes in preterm infants. N Engl J Med. 2006; 355:685-94.

17. Cheong JL, Thompson DK, Wang HX, et al. Abnormal white matter signal on MR imaging is related to abnormal tissue microstructure. AJNR Am J Neuroradiol. 2009;30:623-8.

18. Hart AR, Smith MF, Rigby AS, Wallis LI, Whitby EH. Appearances of diffuse excessive high signal intensity (DEHSI) on MR imaging following preterm birth. Pediatr Radiol. 2010;40:1390-6.

19. Huttenlocher PR, Dabholkar AS. Regional differences in synaptogenesis in human cerebral cortex. J Compar Neurol. 1997;387:167-78.

20. Trivedi R, Gupta RK, Husain N, Rathore RK, Saksena S, Srivastava S, et al. Region-specific maturation of cerebral cortex in human fetal brain: Diffusion tensor imaging and histology. Neuroradiology. 2009;51:567-76.

21. Giedd JN, Blumenthal J, Jeffries NO, Castellanos FX, Liu H, Zijdenbos A, et al. Brain development during childhood and adolescence: A longitudinal MRI study. Nature Neurosci. 1999;2:861-3.

22. Casey BJ, Giedd JN, Thomas KM. Structural and functional brain development and its relation to cognitive development. Biol Psychology. 2000;54:241-57.

23. Cruz-Martinez R, Figueras F, Oros D, Padilla N, Meler E, Hernandez-Andrade E, et al. Cerebral blood perfusion and neurobehavioral performance in full-term small-for-gestational-age fetuses. Am J Obstet Gynecol. 2009;201:474e1-7.

24. Donofrio MT, Bremer YA, Schieken RM, Gennings C, Morton LD, Eidem BW, et al. Autoregulation of cerebral blood flow in fetuses with congenital heart disease: The brain sparing effect. Pediatr Cardiol. 2003;24:436-43.

25. Andropoulos DB, Hunter JV, Nelson DP, Stayer SA, Stark AR, McKenzie ED, et al. Brain immaturity is associated with brain injury before and after neonatal cardiac surgery with high-flow bypass and cerebral oxygenation monitoring. $J$ Thorac Cardiovasc Surg. 2010;139:543-56. 
TABLE E1. Patient characteristics

\begin{tabular}{|c|c|c|c|c|c|}
\hline Characteristic & All CHD $(n=67)$ & $S V(n=10)$ & SVA $(n=16)$ & $2 V(n=27)$ & 2VA $(n=14)$ \\
\hline Males (n) & $38(57)$ & $3(30)$ & $10(62)$ & $15(56)$ & $10(72)$ \\
\hline \multicolumn{6}{|l|}{ Ethnicity (n) } \\
\hline European & $37(55)$ & $3(30)$ & $11(69)$ & $13(48)$ & $10(72)$ \\
\hline Maori & $18(27)$ & $5(50)$ & $2(12)$ & $10(37)$ & $1(7)$ \\
\hline Pacific Island & $8(12)$ & $0(0)$ & 3 (19) & $3(11)$ & $2(14)$ \\
\hline Asian & $4(6)$ & $2(20)$ & $0(0)$ & $1(4)$ & $1(7)$ \\
\hline Antenatal diagnosis (n) & $41(61)$ & $6(60)$ & $16(100)$ & $13(48)$ & $6(43)$ \\
\hline Cesarean delivery (n) & $13(19)$ & $2(20)$ & $2(13)$ & $6(22)$ & $3(21)$ \\
\hline \multicolumn{6}{|l|}{ GA at birth (wk) } \\
\hline Mean & 39 & 38 & 39 & 40 & 39 \\
\hline Range & $36-42$ & $36-40$ & $36-41$ & $37-42$ & $36-41$ \\
\hline \multicolumn{6}{|l|}{ Birth weight (kg) } \\
\hline Mean & 3.3 & 3.2 & 3.3 & 3.4 & 3.1 \\
\hline Range & $2.1-4.7$ & $2.3-4.7$ & $2.7-4.5$ & $2.6-4.2$ & $2.1-3.8$ \\
\hline SGA (n) & $7(11)$ & $1(10)$ & $2(12.6)$ & $1(4)$ & $3(21.3)$ \\
\hline \multicolumn{6}{|l|}{$\mathrm{HC}$ at birth $(\mathrm{cm})$} \\
\hline Mean & 34.9 & 33.7 & 35.0 & 35.0 & 35.1 \\
\hline Range & $31.0-39.0$ & $31.9-37.0$ & $31.0-37.0$ & $32.0-38.0$ & $31.5-39.0$ \\
\hline \multicolumn{6}{|l|}{ Apgar score } \\
\hline \multicolumn{6}{|l|}{ At $1 \mathrm{~min}$} \\
\hline Mean & 8 & 7 & 8 & 8 & 8 \\
\hline Range & $2-10$ & $2-9$ & $2-9$ & $6-9$ & $5-10$ \\
\hline \multicolumn{6}{|l|}{ At $5 \mathrm{~min}$} \\
\hline Mean & 9 & 9 & 9 & 9 & 9 \\
\hline Range & $7-10$ & $7-10$ & $9-10$ & $7-10$ & $8-10$ \\
\hline \multicolumn{6}{|l|}{ Age at MRI (d) } \\
\hline Mean & 8 & 7 & 6 & 9 & 8 \\
\hline Range & $2-23$ & $3-20$ & $2-17$ & $5-23$ & $2-19$ \\
\hline \multicolumn{6}{|l|}{ Weight at MRI (kg) } \\
\hline Mean & 3.3 & 3.2 & 3.3 & 3.5 & 3.1 \\
\hline Range & $2.0-4.9$ & $2.3-4.9$ & $2.6-4.7$ & $2.7-4.2$ & $2.0-3.8$ \\
\hline
\end{tabular}


TABLE E2. Correlations of brain metrics and diffusion values

\begin{tabular}{|c|c|c|c|c|}
\hline Variable & Unadjusted $r$ & $\begin{array}{c}P \\
\text { value }\end{array}$ & Adjusted $r$ & $\begin{array}{c}P \\
\text { value }\end{array}$ \\
\hline \multicolumn{5}{|l|}{ Bifrontal diameter } \\
\hline PLIC/MD & -0.74 & $<.001$ & -0.70 & $<.01$ \\
\hline PLIC/RD & -0.72 & $<.001$ & -0.68 & $<.01$ \\
\hline PLIC/FA & 0.57 & $<.05$ & 0.54 & $<.05$ \\
\hline \multicolumn{5}{|l|}{ Brain biparietal diameter } \\
\hline PLIC/MD & -0.68 & $<.01$ & -0.64 & $<.01$ \\
\hline PLIC/RD & -0.70 & $<.01$ & -0.66 & $<.01$ \\
\hline PLIC/FA & 0.59 & $<.01$ & 0.56 & $<.05$ \\
\hline \multicolumn{5}{|c|}{ Transverse cerebellar diameter } \\
\hline PLIC/MD & -0.52 & $<.05$ & 0.02 & NS \\
\hline PLIC/RD & -0.59 & $<.01$ & -0.28 & NS \\
\hline $\mathrm{PLIC} / \mathrm{FA}$ & 0.55 & $<.05$ & 0.43 & NS \\
\hline $\begin{array}{l}\text { Optic radiation/MD } \\
\text { (CSO level) }\end{array}$ & -0.52 & $<.05$ & -0.41 & NS \\
\hline $\begin{array}{l}\text { Optic radiation/RD } \\
\text { (PLIC level) }\end{array}$ & -0.50 & $<.05$ & -0.28 & NS \\
\hline $\begin{array}{l}\text { Optic radiation/RD } \\
\text { (CSO level) }\end{array}$ & -0.54 & $<.05$ & -0.42 & NS \\
\hline Corticospinal tract/FA & 0.55 & $<.05$ & 0.28 & NS \\
\hline \multicolumn{5}{|l|}{ Brainstem area } \\
\hline PLIC/MD & -0.53 & $<.05$ & -0.30 & NS \\
\hline PLIC/RD & -0.59 & $<.05$ & -0.45 & NS \\
\hline PLIC/FA & 0.55 & $<.05$ & 0.51 & NS \\
\hline Corticospinal tract/FA & 0.51 & $<.05$ & 0.35 & NS \\
\hline
\end{tabular}

